tienen un gran interés en el campo educativo y en el ambiente familiar de cara a conseguir una actuacion que se traduzca en una ayuda eficaz para la evolución del niño. Al mismo tiempo conciencia a los padres de su responsabilidad en la tarea y en el éxito de la misma. Por otro lado, cualquier avance en el conocimiento de la naturaleza y aparición de los miedos, de sus características culturales y geográficas, de su evolución en suma desde nuestro propio contexto, significa un paso adelante en un ámbito tan importante como es la psicología evolutiva. A este respecto son deseables nuevas aportaciones en tal sentido.

Carmen CHICA

\section{R. Fernández Ballesteros y cols. Nuevas aportaciones en evaluación conductual Valencia, Alfaplus, 1981, 290 págs.}

La evaluación conductual se origina como una solución a la crisis del diagnóstico clínico, enraizado en el modelo médico; pero también representa una alternativa renova. dora dentro del análisis de la conducta, estancado en las últimas décadas en una excesiva rigidez paradigmática.

La evaluación conducţual debe insertarse en el marco de la psicología de intervención que supone un intento de adecuación del análisis de la conducta al eclecticismo metodológico e instrumental impuesto por la práctica psicológica, y podemos definirla como «aquella alternativa de la evaluación psicológica a través de la cual se trata de identificar las conductas objeto de estudio - tanto motoras como fisiológicas y cognitivas - así como las variables ambientales $\mathrm{y} / \mathrm{o}$ internas que las mantienen o controlan, con el objetivo de realizar un tratamiento o cualquier otro tipo de intervención psicológica" (Fernández-Ballesteros, 1981, p. 9). A este enfoque pertenece la obra que comentamos, formada por la recopilación de trece trabajos presentados como ponencia en el Congreso Internacional sobre Psicología y Procesos de Socialización, desarrollado en febrero de 1981, en Alicante.

La primera parte lleva por título genérico: Avances metodológicos y la finalidad convergente de los trabajos que incluye es la de realizar una revisión metodológica que clarifique y subsane las deficiencias detectadas en el método observacional, en la objetivización de criterios, en la validez ecológica de la metodología o en las «escalas de puntuación», con tanta frecuencia utilizadas en medición conductual.

En un primer artículo se enmarca a la evaluación conductual con respecto a los procedimientos clásicos de evaluación mediante una revisión de las publicaciones aparecidas en torno al tema. En la conclusión se subraya la insignificante presencia de los métodos directos de evaluación en los planes de estudio nacionales, que privilegian notoriamente los métodos de evaluación indirectos (entrevistas, pruebas proyectivas, autoinformes) en detrimento de una formación más completa de los profesionales de la psicología.

En el segundo trabajo se propone un nuevo método en los registros de observación comportamental, basado en un sistema secuencial de muestreos de tiempo específicos. En el tercer estudio se comprueba la fiabilidad de las puntuaciones obtenidas mediante la técnica de rejilla.

La posterior investigación desarrolla una aproximación cuantitativa a la toma de decisiones y prioridades terapeúticas que en la mayoria de los casos son establecidas a partir de argumentos tan débiles como la experiencia o la intuición del psicólogo. En la alter- 
nativa propuesta por el artículo, la evaluación conductual aportaría datos traducibles a probabilidades que apoyarian cuantitativamente una toma de decisión terapéutica.

En el siguiente trabajo se cuantifican las distorsiones sufridas por seis autoinformes conductuales, ocasionados por los factores de "deseabilidad social» y sinceridad.

En la última comunicación que cierra este primer apartado, se demuestra la poca consistencia de los autoinformes tomados antes y después de las situaciones experimentales, la insignificante correlación de algunos métodos de evaluación en relación a varios o a un mismo contenido y la poca concordancia entre conductas, métodos y contenidos cuando la situación de registro y la muestra no son las mismas.

La segunda parte del libro: Estudios sobre técnicas está compuesta por dos trabajos en los que se utilizan desde una perspectiva conductual, algunos instrumentos de evaluación tradicionales, considerando las respuestas de los sujetos como datos de su repertorio conductual.

En el primero se trata la prueba de Rorschach como muestreo de respuestas perceptivas de los sujetos. En el segundo se presentan dos escalas de socialización perfectamente validadas, y se utilizan para la recopilación de factores relacionados con las con. ductas de socialización observables en la es. cuela.

La tercera y última parte de esta obra: Evaluación de transtornos conductuales, recoge cinco estudios referidos a las aplicacio- nes clínicas de la evaluación conductual. El primero de ellos representa un intento de evaluar un transtorno de raíz motora, como es la tartamudez. En el segundo se presenta un inventario de autoinformes para la evaluación de transtornos sexuales. En el siguiente estudio los autores emplean una respuesta motora, adquirida mediante condicionamiento operante, como fórmula predictiva en la eficacia del tratamiento de conductas etiquetadas como autistas.

A continuación, en un nuevo trabajo, se describe una estrategia de aprendizaje cognitivo en niños con déficits culturales a partir de un entrenamiento cognitivo específico que mejora significativamente las puntuaciones obtenidas por los sujetos en el test de Raven.

Con un artículo en el que se introducen. una serie de pruebas cognitivas mediante las cuales se intenta establecer el riesgo existente en la emisión de conductas "esquizoides", finaliza el libro.

A partir de la evaluación conductual, el análisis de la conducta ya no recae únicamente sobre las respuestas motoras, sino que se evalúan las distintas modalidades de respuesta, sean o no encubiertas. Los profesionales de la práctica psicológica en todas sus vertientes, obligados en numerosas ocasiones a buscar soluciones inmediatas en es. quemas pseudocientíficos, agradecerán el pragmatismo y la flexibilidad que aporta este nuevo enfoque al análisis conductual.

C. Monereo 